\title{
Validated Multivariate Models Predicting the Growth Response to GH Treatment in Individual Short Children with a Broad Range in GH Secretion Capacities
}

\author{
KERSTIN ALBERTSSON WIKLAND, BERIT KRISTRÖM, STEN ROSBERG, BIRGITTA \\ SVENSSON, AND ANDREAS F.M. NIEROP
}

International Pediatric Growth Research Center, Department of Pediatrics University of Göteborg, SE-41685 Göteborg [K.A.W., B.K., S.R., B.S.]; Department of Pediatrics, Umeå University, SE-90185

Umeå, Sweden [B.K.]; and Muvara bv, Tijmtuin 8, 2353 PH Leiderdorp, the Netherlands [A.F.M.N.]

\begin{abstract}
The aim of the study was to develop and validate models that could predict the growth responses to GH therapy of individual children. Models for prediction of the initial one and 2-y growth response were constructed from a cohort of 269 prepubertal children (Model group) with isolated GH deficiency or idiopathic short stature, using a nonlinear multivariate data fitting technique. Five sets of clinical information were used. The "Basic model" was created using auxological data from the year before the start of GH treatment and parental heights. In addition to Basic model data, the other four models included growth data from the first 2 y of life, or IGF-I, or GH secretion estimated during a provocation test (AITT) or a spontaneous GH secretion profile.

The performance of the models was validated by calculating the differences between predicted and observed growth responses in 149 new GH treated children (Validation group) who fulfilled the inclusion criteria used in the original cohort. The SD of these differences $\left(\mathrm{SD}_{\text {res }}\right)$ in the validation group was compared with the $\mathrm{SD}_{\text {res }}$ for the model group. For the $1 \mathrm{st} \mathrm{y}$, the $\mathrm{SD}_{\text {res }}$ for the
\end{abstract}

\section{ABSTRACT}

Basic model was 0.28 SDscores. The lowest $\mathrm{SD}_{\text {res }}$ (0.19 SDscores), giving the most narrow prediction interval, was achieved adding the $24 \mathrm{~h} \mathrm{GH}$ profile and data on growth from the first $2 \mathrm{y}$ of life to the Basic model. The models presented permit estimation of $\mathrm{GH}$ responsiveness in children over a broad range in $\mathrm{GH}$ secretion, and with an accuracy of the models substantially better than when using maximal GH response during an provocation test. The predicted individual growth response, calculated using a computer program, can serve as a guide for evidence-based decisions when selecting children to GH treatment. (Pediatr Res 48: $475-484,2000$ )
GHD, GH deficiency
GHI, GH insensitivity
ISS, idiopathic short stature
IGFBP-3, IGF binding protein 3
AITT, arginin-insulin tolerance test
$\mathbf{G H}_{\mathbf{m a x}}$, the estimated maximal GH level

The diagnosis of severe GH deficiency (GHD) on the one hand or complete GH insensitivity (GHI) on the other, usually is obvious in the short child in whom appropriate studies have excluded other causes for growth failure. Among children forming the continuum between these two extremes, diagnosis is more challenging; that is, children with partial GHD or those

Received September 7, 1999; accepted April 21, 2000

Correspondence and reprint requests: K. Albertsson Wikland, University of Göteborg, Department of Pediatrics, International Pediatric Growth Research Center, Queen Silvias Children's Hospital, S-416 85 Göteborg, Sweden.

This work was supported by grants from Swedish Medical Research Council (7509), Barnhusfonden, The Jerring Foundation, The Samariten Foundation, The Medical Faculties in Umeå and Göteborg Universities, Wilhelm and Martina Lundgrens Foundation, The May Flower Foundation, West Sweden Region (3160) and Pharmacia.

Part of this study has been presented at the 5th joint meeting of the European Society for Pediatric Endocrinology and the Lawson Wilkins Pediatric Endocrine Society, Stockholm 1997. considered to have partial GHI, who may be classified as idiopathic short stature (ISS). Despite investigations and discussions aimed at attaining consensus on the diagnostic discrimination between GHD and ISS $(1,2)$, none of the clinical measures used to date provide a reliable means for categorizing these patients and for predicting the value of GH therapy (3). The effect of the GH axis on statural growth in an individual child depends on the interaction between GH secretion and GH responsiveness. With better understanding of conditions causing GH resistance (4-7), the need to consider responsiveness to $\mathrm{GH}$, as well as secretion of $\mathrm{GH}$ when interpreting the growth of a child has become more apparent.

Traditionally, the diagnosis of GHD relies on the interpretation of the serum GH concentrations attained during at least two GH provocation tests. However, the lack of convergence 
between GH response to provocation tests and growth response to GH therapy has led many clinicians to disregard the $\mathrm{GH}$ stimulation test results, and to use the first y growth response to GH treatment to determine need for treatment (8). Diagnosis, however, should not be based on auxological criteria alone (9). Similarly, to rely solely on GH provocation tests can be misleading, as only $33 \%$ of the variance in growth response to $\mathrm{GH}$ treatment is explained by the results of conventional diagnostic procedures (10). Many now accept that the diagnosis of GHD must be based on an integrated judgment from many variables (11). However, with addition of biochemical markers such as IGF-I, IGFBP-3, and leptin to the diagnostic evaluation, not more than $41 \%$ to $58 \%$ of the variance in growth response could be explained $(12,13)$. With addition of the spontaneous 24-h GH secretion profile from a group of 60 children, the variance in growth response explained could be increased to about $70 \%$ (unpublished).

Prediction models are used widely in medicine with the aim that outcome of therapies in individual patients can be determined. The usefulness of such models is defined by how well they perform in practice, rather than the level of statistical significance they achieve. Consequently, it is crucial that the model be tested using data from patients who fulfill the inclusion criteria for the model, but whose data were not used in deriving the model (14).

The aim with this study was to develop models for prediction of the one and two-y growth responses to a standardized GH treatment in individual slowly growing or short prepubertal children considered to have isolated GHD or ISS. The predicted individual growth response can be used as an estimate of $\mathrm{GH}$ secretion in relation to $\mathrm{GH}$ responsiveness and serve as a guide for better evidence-based decision making with regard to growth promoting treatment (15).

\section{PATIENTS AND METHODS}

\section{Study Design}

The reliability and stability of prediction models depends on the inclusion of a wide range of values in the variable used. In the present study group, therefore, we included short children covering the entire continuum of GH secretory capacities, ranging from very low (GHD) to high (ISS) values. The outcome variable for the study, the growth response to $\mathrm{GH}$ treatment, appears also as a continuum when related to $\mathrm{GH}$ secretory capacity (Fig. 1). As no distinct cut-off limit could be discerned, and in keeping with the study aim, children with and without the classic definition of GHD were analyzed together.

Data derived from two separate groups of children were used in the study. The groups differed only in the calendar time at which they started GH treatment. Data from the first ("model") group, were used to calculate the prediction functions, while data from the second ("validation") group, who started GH therapy after recruitment to the prediction model group was closed, were used only to test the validity of the prediction models (14).

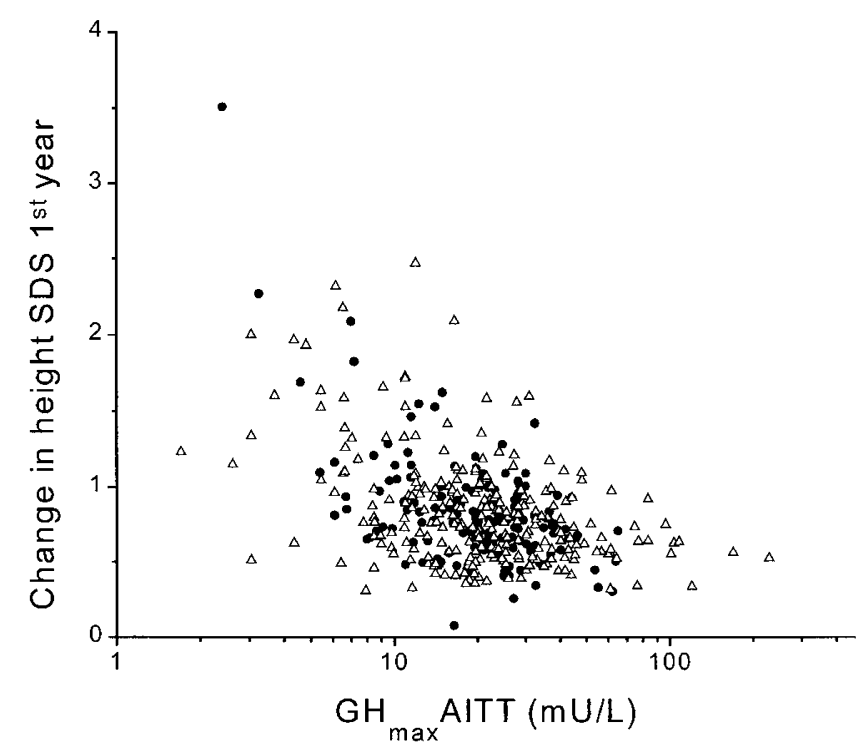

Figure 1. Growth response to the 1 st y of $\mathrm{GH}$ treatment $(0.1 \mathrm{U} / \mathrm{kg} / \mathrm{d}, 0.033$ $\mathrm{mg} / \mathrm{kg} / \mathrm{d})$ vs maximum serum GH concentration during an AITT $\left(\mathrm{GH}_{\max } \mathrm{AITT}\right)$ in the model group $(\Delta)$ and in the validation group $(-)$ of short prepubertal children diagnosed as having isolated GHD or ISS. In clinical practice 32 $\mathrm{mU} / \mathrm{L}$ (WHO IRP 80/505) is used as the cut-off point for diagnosis of GHD. This corresponds to $20 \mathrm{mU} / \mathrm{L}$ with the previously used standard (WHO IRP $66 / 217$; (24)). A continuum in the $\mathrm{GH}_{\max }$ response for the GHD and ISS children is observed, as is a continuum in the growth response to $\mathrm{GH}$ treatment. Note the wide range in growth responses, indicating a wide range in $\mathrm{GH}$ responsiveness when the patients are treated with the same weight-based GH dose.

\section{Patients}

Prediction model group. This group of 269 prepubertal short or slowly growing children (45 girls, 224 boys) was of Caucasian origin, and was mainly Swedish. They had been treated with $\mathrm{GH}, 0.1 \mathrm{U} / \mathrm{kg} / \mathrm{d}(0.033 \mathrm{mg} / \mathrm{kg} / \mathrm{d})$, for at least $1 \mathrm{y}$, and 213 (33 girls, 180 boys) had been treated for $2 \mathrm{y}$. They were either children with isolated idiopathic GH insufficiency who were included in the Swedish National Registry for GH treatment $(n=173)$, or short children without GH insufficiency who were included in clinical trials of GH treatment $(n=96)$.

Children with dysmorphic syndromes or chronic diseases, other than those related to impaired GH secretion or action, were excluded. The children were prepubertal, as defined by breast stage 1 (16) or testicular volume below $4 \mathrm{~mL}$ (17). Boys, however, who have a testicular volume between 4 and $6 \mathrm{~mL}$ have not yet started their pubertal growth spurt (10), and fit the childhood component of the growth standard from the infant, childhood and puberty (ICP) model (18). Two of the 224 boys in the model group and 6 of the 129 boys in the validation group had a testicular volume between 4 and $6 \mathrm{~mL}$ at the start of the study and were included in the analysis, as their testicular volume was still $<6 \mathrm{~mL}$ after 1 and 2 y of treatment. The characteristics of the patients in the prediction model group are given in Table 1 and of a subgroup for which spontaneous $24 \mathrm{~h}$ GH profiles were available, in Table 2 .

Validation group. Children in the validation group were selected using the same inclusion criteria and clinical evaluation procedures used for the prediction model group. This group consisted of 149 children ( 20 girls, 129 boys), 129 from 
Table 1. Characteristics of the children included in the prediction model group and the validation group

\begin{tabular}{|c|c|c|c|c|c|c|c|c|c|c|}
\hline \multirow[b]{2}{*}{ Variable } & \multicolumn{5}{|c|}{$\begin{array}{c}\text { Prediction model group } \\
(\mathrm{n}=269 ; 45 \text { girls, } 224 \text { boys })\end{array}$} & \multicolumn{5}{|c|}{$\begin{array}{c}\text { Validation group } \\
(\mathrm{n}=149 ; 20 \text { girls, } 129 \text { boys })\end{array}$} \\
\hline & Median & Mean & SD & Min & Max & Median & Mean & $\mathrm{SD}$ & Min & Max \\
\hline Gestational age (weeks) & 40.0 & 39.3 & 1.9 & 30.0 & 43.0 & 39.0 & 39.1 & 1.8 & 32.0 & 43.0 \\
\hline Height SDscore & -0.89 & -0.82 & 0.96 & -3.14 & 2.72 & -0.87 & -0.77 & 0.99 & -2.43 & 1.92 \\
\hline Weight SDscore & -0.60 & -0.53 & 1.06 & -2.78 & 2.61 & -0.67 & -0.61 & 0.88 & -2.50 & 1.59 \\
\hline Height SDscore & -2.77 & -2.81 & 0.66 & -6.00 & -0.91 & -2.58 & -2.63 & 0.71 & -6.71 & -1.12 \\
\hline Weight SDscore & -1.61 & -1.55 & 0.65 & -3.89 & 2.05 & -1.57 & -1.55 & 0.57 & -3.47 & 0.98 \\
\hline Weight for height ${ }_{\text {SDscore }}$ SDscore & 0.79 & 0.87 & 0.94 & -1.50 & 6.02 & 0.64 & 0.69 & 0.75 & -1.07 & 3.82 \\
\hline BMI $\left(\mathrm{kg} / \mathrm{m}^{2}\right)$ & 15.6 & 15.8 & 1.7 & 12.3 & 25.2 & 15.6 & 15.7 & 1.3 & 13.2 & 20.3 \\
\hline $\begin{array}{l}\text { Change in height SDscore during pretreatment } \\
\text { year }\end{array}$ & 0.02 & 0.01 & 0.22 & -0.61 & 0.95 & 0.01 & 0.03 & 0.25 & -0.68 & 1.06 \\
\hline $\begin{array}{l}\mathrm{GH}_{\max } \text { during AITT (mU/L, polyclonal, WHO } \\
\text { IRP } 80 / 505 \text { ) }\end{array}$ & 20.5 & 26.2 & 24.2 & 0.1 & 229.4 & 20.75 & 22.33 & 11.99 & 2.41 & 65.10 \\
\hline \multicolumn{11}{|l|}{ Auxology after the start of treatment } \\
\hline Change in height SDscore 1st y & 0.77 & 0.84 & 0.37 & 0.31 & 2.47 & 0.79 & 0.85 & 0.39 & 0.08 & 3.51 \\
\hline Change in height SDscore during $2 \mathrm{y}$ & 1.26 & 1.32 & 0.54 & 0.42 & 3.20 & 1.22 & 1.28 & 0.64 & 0.34 & 5.54 \\
\hline
\end{tabular}

Table 2. Characteristics of the children included in the 24-h profile prediction model group and the validation group

\begin{tabular}{|c|c|c|c|c|c|c|c|c|c|c|}
\hline \multirow[b]{2}{*}{ Variable } & \multicolumn{5}{|c|}{$\begin{array}{c}\text { Prediction model group } \\
(\mathrm{n}=107 ; 18 \text { girls, } 89 \text { boys })\end{array}$} & \multicolumn{5}{|c|}{$\begin{array}{c}\text { Validation group } \\
(\mathrm{n}=32 ; 2 \text { girls, } 30 \text { boys })\end{array}$} \\
\hline & Median & Mean & SD & Min & $\operatorname{Max}$ & Median & Mean & SD & Min & $\operatorname{Max}$ \\
\hline Gestational age (weeks) & 39.0 & 38.9 & 2.2 & 31.0 & 42.0 & 40.0 & 39.4 & 1.5 & 35.0 & 42.0 \\
\hline Height SDscore & -0.87 & -0.91 & 0.94 & -3.37 & 2.17 & -1.07 & -1.02 & 1.07 & -2.43 & 1.59 \\
\hline Weight SDscore & -0.67 & -0.57 & 1.01 & -2.50 & 2.61 & -0.92 & -0.78 & 0.97 & -2.44 & 1.59 \\
\hline Height SDscore & -2.60 & -2.76 & 0.64 & -6.00 & -1.48 & -2.52 & -2.53 & 0.59 & -4.10 & -1.76 \\
\hline Weight SDscore & -1.57 & -1.58 & 0.57 & -3.89 & 0.01 & -1.45 & -1.40 & 0.71 & -2.77 & 0.98 \\
\hline Weight for height $_{\text {SDscore }}$ SDscore & 0.64 & 0.78 & 0.82 & -1.02 & 3.81 & 0.82 & 0.81 & 0.87 & -1.07 & 3.82 \\
\hline BMI $\left(\mathrm{kg} / \mathrm{m}^{2}\right)$ & 15.6 & 15.7 & 1.6 & 12.7 & 20.6 & 15.7 & 16.0 & 1.6 & 13.3 & 20.3 \\
\hline $\begin{array}{l}\text { Change in height SDscore during pretreatment } \\
\text { year }\end{array}$ & 0.01 & 0.04 & 0.21 & -0.38 & 0.95 & 0.05 & 0.09 & 0.19 & -0.20 & 0.67 \\
\hline $\begin{array}{l}\mathrm{GH}_{\max } \text { during AITT (mU/L, polyclonal, WHO } \\
\text { IRP 80/505) }\end{array}$ & 20.8 & 34.6 & 32.3 & 1.7 & 229.4 & 24.6 & 28.2 & 17.4 & 5.4 & 65.1 \\
\hline $\begin{array}{l}\mathrm{GH}_{\max } \text { during } 24 \mathrm{~h} \text { profile (mU/L, polyclonal, } \\
\text { WHO IRP } 80 / 505 \text { ) }\end{array}$ & 34.9 & 39.0 & 23.7 & 3.9 & 134.0 & 29.3 & 35.8 & 39.3 & 7.2 & 235.4 \\
\hline \multicolumn{11}{|l|}{ Auxology after the start of treatment } \\
\hline Change in height SDscore 1st year & 0.79 & 0.73 & 0.25 & 0.32 & 1.63 & 0.66 & 0.70 & 0.22 & 0.30 & 1.14 \\
\hline Change in height SDscore during $2 \mathrm{y}$ & 1.22 & 1.18 & 0.46 & 0.48 & 3.14 & 1.20 & 1.06 & 0.38 & 0.34 & 1.72 \\
\hline
\end{tabular}

the Swedish National Registry for GH treatment and 20 from ongoing clinical studies of $\mathrm{GH}$ treatment for short children without GH insufficiency. All 149 children were followed for $1 \mathrm{y}( \pm 3 \mathrm{mo})$ and 109 (13 girls, 96 boys) were followed for $2 \mathrm{y}$, $( \pm 3 \mathrm{mo})$. The characteristics of the patients in the validation group are given in Tables 1 and 2 .

\section{Study Protocol}

Pretreatment investigations. The investigations were performed during the pretreatment year, including a GH stimulation test (arginine-insulin tolerance test, AITT) as described previously (10). A spontaneous 24-h GH-profile with samples 
taken every 20 or 30 min (19) was also obtained from 107 children, (18 girls, 89 boys) in the prediction group and 32 children ( 2 girls, 30 boys) in the validation group. Blood samples for IGF-I and IGFBP-3 were drawn at the start of treatment from 106 children in the prediction model group, and from 95 children in the validation group. The clinical characteristics of the groups of children from which only auxological information was used were not different from those in which serum IGF-I and IGFBP-3 or $24 \mathrm{~h}$ GH profiles were obtained.

Treatment. All children underwent the same regimen of daily s.c. injections of $\mathrm{GH} 0.1 \mathrm{U} / \mathrm{kg}(0.033 \mathrm{mg} / \mathrm{kg})$.

\section{Auxological Methods}

Information on gestational age, birth weight, and birth length was collected from the Swedish Medical Birth Registry. The growth of the children was recorded at health care units from birth until inclusion in the study, i.e. 1 y $( \pm 3 \mathrm{mo})$ before the start of GH treatment. Thereafter, for the majority of the children, height was measured using a Harpenden stadiometer at pediatric units. Height data were transformed into SDscores for age and sex using the childhood component of the infancy, childhood and puberty (ICP) growth model of Karlberg et al. (18), and weight data according to Karlberg et al. (20). Weight for height data also were transformed into SDscores $\left(\mathrm{WH}_{\mathrm{SD}}\right.$ scoreSDscore; (21). Parental heights were expressed in SDscores (20). The intra-familial height deficit (diffSDscore; the difference between the height SDscore of each child at the start of GH treatment and the mid-parental height expressed in SDscore) was calculated.

\section{Hormone Analysis}

$\boldsymbol{G H}$. Serum concentrations of GH from the AITT were generally analyzed using an immunoradiometric assay with polyclonal antibodies and the WHO IRP 80/505 Standard (Pharmacia Diagnostics AB, Uppsala, Sweden). If another method or an earlier standard was used, the GH concentrations were transformed into comparable levels using transformation factors derived in our laboratory (22-24). The detection limit of the assay is $0.4 \mathrm{mU} / \mathrm{L}$ and the intra-assay coefficients of variation are $7.1 \%, 1.9 \%$ and $2.3 \%$ at concentrations of $1,5-20$ and $30 \mathrm{mU} / \mathrm{L}$, respectively. The interassay coefficients of variation are $14 \%, 4 \%, 4 \%$, and $7 \%$ at concentrations of $1,21,30$, and $46 \mathrm{mU} / \mathrm{L}$, respectively.

Analyses of the 24-h GH profiles were conducted in the same laboratory using an immunoradiometric assay and the WHO IRP 80/505 standard (Pharmacia Diagnostics AB, Uppsala, Sweden). The results from the GH profiles were analyzed with the Pulsar program (25) giving the calculated baseline, number of peaks, peak amplitudes, and area under the curve above the zero line $\left(\mathrm{AUC}_{0}\right)$ or above the calculated baseline $\left(\mathrm{AUC}_{\mathrm{b}}\right)$. The $\mathrm{AUC}$ was used to calculate the $\mathrm{GH}$ secretion rate (26), which was used in the analysis along with the maximal $\mathrm{GH}$ peak during the $24 \mathrm{~h} \mathrm{GH}$ profile $\left(\mathrm{GH}_{\max } 24 \mathrm{~h}\right), \mathrm{AUC}_{0}$ and $\mathrm{AUC}_{\mathrm{b}}$ (27).

IGF-I. An IGFBP-blocked RIA was used without extraction of the sample, and in the presence of an approximately 250 - fold excess of IGF-II (Mediagnost GmbH, Tübingen, Germany) (28).

IGFBP-3. An RIA was used as previously reported (28). Serum concentrations of IGF-I and IGFBP-3 were converted into SDscore (29).

\section{STATISTICS}

\section{General Considerations about Prediction Models}

How well a model fits (is adapted to) the data can be evaluated on a group level; the value of $\mathrm{R}^{2}$ is an estimate of how the observed values are correlated with the fitted values. In the final analysis usefulness of a model is determined by how well it works in practice, not the level of statistical significance. Therefore it is crucial that the model should be tested (validated), using data from patients fulfilling the inclusion criteria for the model, but who were not among the patients whose data were used to derive the model. The model is considered to be statistically valid if the $\mathrm{SD}_{\text {res }}$ for the validation group of patients is in the same range as observed for the group of patients from whose data the model was derived. This procedure is referred to as "validation" or "generalization" (14).

With focus on the validation group, the $\mathrm{R}^{2}$ analysis is too sensitive for possible extremes, and insensitive for shifting of the mean predicted value. We therefore solely present analyses of the residuals, i.e. differences between the observed outcomes and those fitted by the models for the modeling group, or predicted by the models for the validation group.

The residuals were calculated and the SD of these differences was evaluated as the $\mathrm{SD}$ of the residuals $\left(\mathrm{SD}_{\mathrm{res}}\right)$. This is a measure of the root mean squared differences between observed and predicted outcome.

\section{Modeling}

There was no standard statistical method available for the approach used in the present study. The technique used is best described as nonlinear data fitting (empirical curve fitting) and empirical testing. The nonlinear approach was chosen because of a nonlinear relation was found between growth response and other variables. The following modeling guidelines were applied.

For each predictor variable, the form of the transformation curve that gives the best overall prediction result was determined (30), estimated by as high a correlation as possible. The slope of the tails of the optimal function was restricted to stabilize the nonlinear models. Optimal transformed variables were selected. Interactions of optimal transformed variables in the nonlinear multiple regression were included, if there was a contribution to the prediction. Transformed intermediate factors were not selected, because of the danger of overfitting. In the present approach, overfitting was prevented by selecting stepwise subsets of nonlinear transformed original variables that gave the best overall prediction result, and by evaluating the predictive power by cross-validation by successively omitting different subgroups of model patients accounting for at least $20 \%$ of the patients in a first modeling step, and thereafter 
predicting the response of the omitted subgroups. As the growth response curve is nonlinear, a nonlinear correction for differences in measurement time ( $1 \mathrm{y} \pm 3 \mathrm{mo})$ was developed. The modeler (AN) had no access to the data from the validation group. Testing of the final prediction models with the validation group children was performed by others (S.R., B.S.) on another computer. A computer program for calculation of the prediction was constructed, using the algorithms presented in the appendix.

For comparison, a traditional multiple stepwise linear regression analysis was applied to those variables associated (at $p<0.10$ ) with the growth response to GH treatment, using the model group of children. Correlations were tested using Pitman's nonparametric permutation test (31). Algorithms were constructed for each variant of the models, and used for prediction of the growth response for the children in the validation group.

Ethics. The studies were approved by the Ethics Committee of the Medical Faculties of the Universities of Göteborg, Lund, Linköping, Uppsala and Umeå and of the Karolinska Institute. Informed consent was obtained from the parents of each child and, from the child, where appropriate.

\section{RESULTS}

\section{Prediction Models}

Five sets of clinical information were used; 1) auxology alone from close to the start of treatment; or auxology plus 2) data on growth before $2 y$ of age, 3) IGF-I and IGFBP-3, 4) the maximal serum GH concentration in response to the AITT $\left(\mathrm{GH}_{\max } \mathrm{AITT}\right)$, or 5) $\mathrm{GH}$ estimates from the spontaneous $24-\mathrm{h}$ GH profile. The auxological variables made available for modeling, and those selected in the models, are shown in Table 3 . The growth response outcome was expressed as the change in height SDscore for 1 or $2 \mathrm{y}$ of GH treatment. The equations for the models are given in the Appendix.

Basic model. The Basic model was created using only auxological information from $1 \mathrm{y}$ before the start and from the start of GH treatment, together with parental heights in 269 children (Table 3). The result is given in Table 4. The results from the validation group of children $(\mathrm{n}=149)$ were consistent $\left(\mathrm{SD}_{\text {res }}=0.24\right)$ with the results from the model group $\left(\mathrm{SD}_{\text {res }}=0.28\right)$, indicating that it is statistically valid. A plot of the studentized residuals in relation to the predicted growth response for the validation group is presented in Fig. 2.

Early growth model. The variables of length, weight, and weight/length at birth and at 1 and $2 \mathrm{y}$ of age were added to the Basic model. In Table 3 the available variables are listed and the variables found informative and included in the models are marked. Results are given in Table 4.

$\boldsymbol{G H}_{24 h}$ model. Different variables from the 24-h GH profile were added to the Basic model to produce the $\mathrm{GH}_{24 \mathrm{~h}}$ model (Table 4). The maximum GH peak over $24-\mathrm{h}\left(\mathrm{GH}_{\max } 24 \mathrm{~h}\right)$ was the most informative variable. The second most informative variable from the profile was the area under the curve above baseline $\left(\mathrm{AUC}_{\mathrm{b}}\right)$ (data not shown).

$\mathrm{GH}_{24 h}$ combined with early growth model. Both the early growth variables and the $\mathrm{GH}_{\max } 24 \mathrm{~h}$ variable were added to the
Table 3. Auxological variables available and selected for the statistical analyses in the basic model (top) and the early growth model (bottom)

\begin{tabular}{|c|c|c|}
\hline Auxological variables & Available & Selected \\
\hline \multicolumn{3}{|l|}{ BASIC MODEL } \\
\hline \multicolumn{3}{|l|}{ At $1 \mathrm{y}$ before the start of treatment } \\
\hline Height SDscore & $\mathrm{x}$ & $\mathrm{x}$ \\
\hline Weight SDscore & $\mathrm{x}$ & \\
\hline $\mathrm{WH}_{\text {SDscore }}$ SDscore & $\mathrm{x}$ & \\
\hline \multicolumn{3}{|l|}{ At the start of treatment } \\
\hline Sex & $\mathrm{x}$ & $\mathrm{x}$ \\
\hline Height SDscore & $\mathrm{x}$ & $\mathrm{x}$ \\
\hline Weight SDscore & $\mathrm{x}$ & \\
\hline $\mathrm{WH}_{\text {SDscore }}$ SDscore & $\mathrm{x}$ & $\mathrm{x}$ \\
\hline BMI & $\mathrm{x}$ & \\
\hline Age & $\mathrm{x}$ & $\mathrm{x}$ \\
\hline Maternal height SDscore & $\mathrm{x}$ & $\mathrm{x}$ \\
\hline Paternal height SDscore & $\mathrm{x}$ & $\mathrm{x}$ \\
\hline \multicolumn{3}{|l|}{ Difference during pretreatment year } \\
\hline$\Delta$ height SDscore & $\mathrm{x}$ & $\mathrm{x}$ \\
\hline$\Delta$ weight SDscore & $\mathrm{x}$ & \\
\hline$\Delta \mathrm{WH}_{\text {SDscore }}$ SDscore & $\mathrm{x}$ & \\
\hline \multicolumn{3}{|l|}{ EARLY GROWTH MODEL } \\
\hline \multicolumn{3}{|l|}{ At birth } \\
\hline Gestational age & $\mathrm{x}$ & $\mathrm{x}$ \\
\hline Length SDscore & $\mathrm{x}$ & \\
\hline Weight SDscore & $\mathrm{x}$ & $\mathrm{x}$ \\
\hline $\mathrm{WH}_{\text {SDscore }}$ SDscore & $\mathrm{x}$ & \\
\hline $\begin{array}{l}\text { Age at onset of the childhood } \\
\text { component* }\end{array}$ & $\mathrm{x}$ & \\
\hline \multicolumn{3}{|l|}{ At 1 and $2 y$ of age } \\
\hline Height SDscore & $\mathrm{x}$ & \\
\hline Weight SDscore & $\mathrm{x}$ & \\
\hline $\mathrm{WH}_{\text {SDscore }}$ SDscore & $\mathrm{x}$ & \\
\hline At $1 \mathrm{y}$ before the start of treatment & As basic & As basic \\
\hline At the start of treatment & As basic & As basic \\
\hline \multicolumn{3}{|l|}{$\begin{array}{l}\text { Difference from birth to } 1 \text { and } 2 \mathrm{y} \text { of } \\
\text { age }\end{array}$} \\
\hline$\Delta$ height SDscore & $\mathrm{x}$ & \\
\hline$\Delta$ weight SDscore & $\mathrm{x}$ & \\
\hline$\Delta \mathrm{WH}_{\text {SDscore }}$ SDscore & $\mathrm{x}$ & \\
\hline \multicolumn{3}{|l|}{$\begin{array}{l}\text { Difference/year from } 1 \text { and } 2 \text { y of age, } \\
\text { respectively, to start of treatment }\end{array}$} \\
\hline$\Delta$ height SDscore & $\mathrm{x}$ & $\mathrm{x}, 2 \mathrm{yrs}$ \\
\hline$\Delta$ weight SDscore & $\mathrm{x}$ & \\
\hline$\Delta \mathrm{WH}_{\text {SDscore }}$ SDscore & $\mathrm{x}$ & $\mathrm{x}, 1 \mathrm{yr}$ \\
\hline
\end{tabular}

$* \operatorname{Ref} 18$

Basic model. This resulted in the model with the lowest $\mathrm{SD}_{\text {res }}$ (0.19) (Table 4).

$\mathrm{GH}_{\text {max }}$ AITT, IGF-I SDscore and IGF-binding protein (IGFBP)-3 SDscore added to Basic model. The $\mathrm{GH}_{\max }$ AITT, the IGF-I SDscore and the IGFBP-3 SDscore were evaluated by adding their values to the Basic model. Both $\mathrm{GH}_{\max } \mathrm{AITT}$ and the IGF-I SDscore were predictive, but at an intermediate magnitude. The $\mathrm{SD}_{\text {res }}$ were 0.27 and 0.24 , respectively (Table 4). The IGFBP-3 SDscore values were less informative than the IGF-I SDscores or the GH values from the provocation test, and did not improve the prediction beyond that achieved from the Basic model.

\section{Comparison of the Results of Nonlinear Models}

The best 1st y model (the $\mathrm{GH}_{24 \mathrm{~h}}$ early growth model with the most extensive pretreatment information) had a $\mathrm{SD}_{\text {res }}$ of 
Table 4. Model reliability, comparison of the model group with the validation group (non-linear multiple regression)

\begin{tabular}{|c|c|c|c|c|}
\hline & \multicolumn{2}{|c|}{ Model group } & \multicolumn{2}{|c|}{ Validation group } \\
\hline & $\mathrm{n}$ & $\mathrm{SD}_{\text {res }}$ & $\mathrm{n}$ & $\mathrm{SD}_{\text {res }}$ \\
\hline \multicolumn{5}{|l|}{1 year } \\
\hline Basic model $+\mathrm{GH}_{\max } \mathrm{AITT}$ & 266 & 0.268 & 145 & 0.224 \\
\hline Basic model + Early growth & 227 & 0.242 & 149 & 0.235 \\
\hline Basic model + IGF-I & 106 & 0.239 & 96 & 0.247 \\
\hline \multicolumn{5}{|l|}{2 years } \\
\hline Basic model & 213 & 0.390 & 110 & 0.363 \\
\hline Basic model $+\mathrm{GH}_{\max }$ AITT & 210 & 0.381 & 107 & 0.333 \\
\hline Basic model + Early growth & 187 & 0.342 & 110 & 0.348 \\
\hline Basic model + IGF-I & 81 & 0.335 & 72 & 0.381 \\
\hline Basic model $+\mathrm{GH}_{\max } 24 \mathrm{~h}$ & 79 & 0.292 & 25 & 0.354 \\
\hline
\end{tabular}

$\mathrm{SD}_{\text {res }}=$ root mean square error of the residuals.

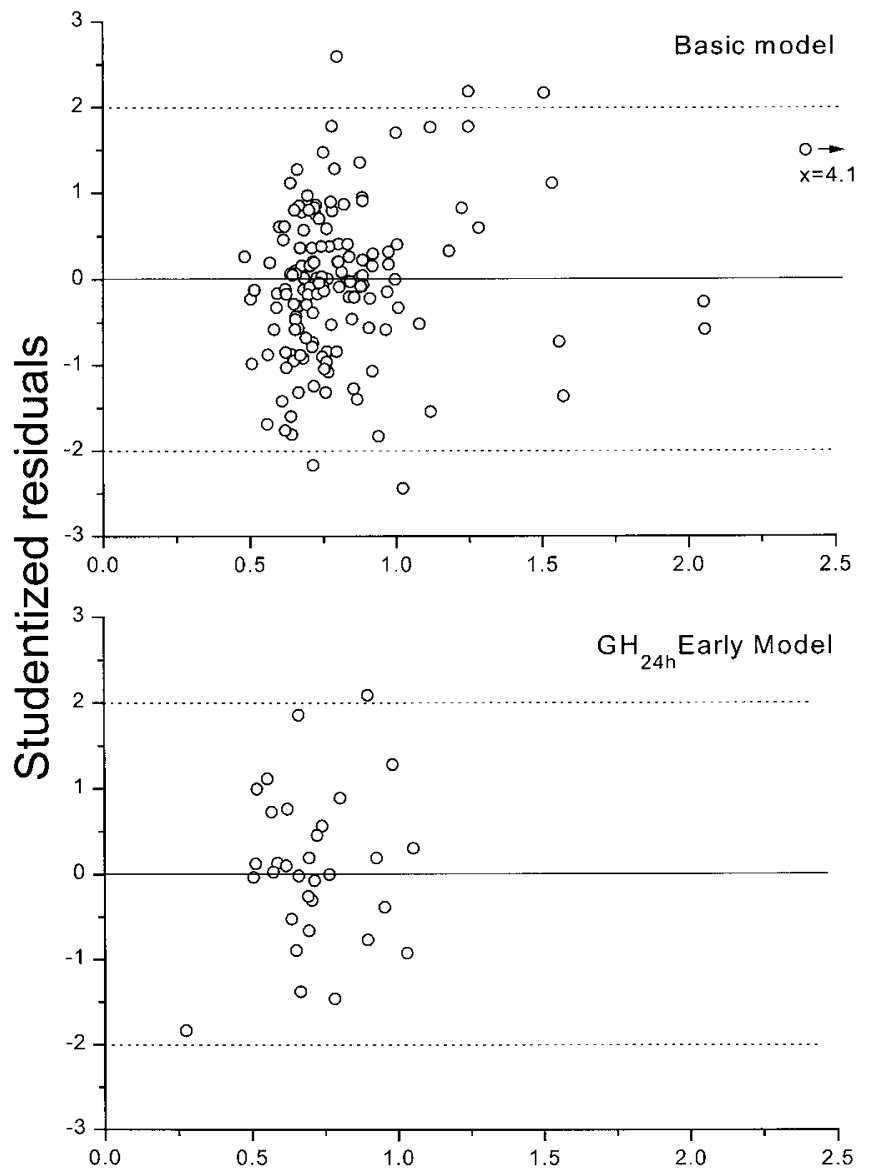

Predicted $1^{\text {st }}$ year growth response (SDscore)

Figure 2. Individual studentized residuals (residuals $/ \mathrm{SD}_{\text {res }}$ ) in relation to predicted 1st y growth responses using the Basic model (top), and the $\mathrm{GH}_{24 \mathrm{~h}}$ Early (bottom) using the data of children in the validation group $(\mathrm{n}=149)$.

0.19 SDscore, gave height predictions in the validation group within 0 to 0.25 SDscore for $84 \%$ of the children, and between 0.25 to 0.50 SDscore for the remaining $16 \%$ (Fig. 3). We observed good extrapolation properties for all models. In Table 1 the maximum change in height SDscore during $2 \mathrm{y}$ of treatment was 3.20 for the prediction model group and 5.54 for the validation group. While this is far outside the modeling

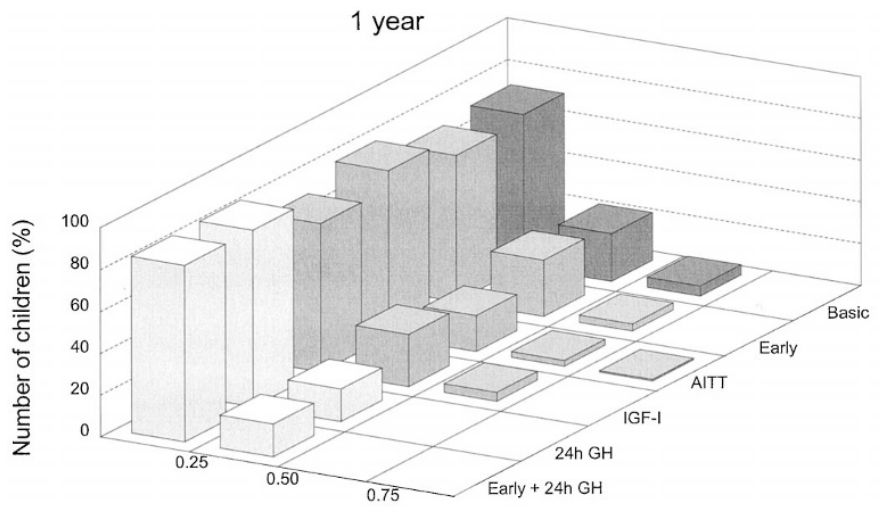

| Observed $\triangle$ SDS - Predicted $\triangle S D S$ |

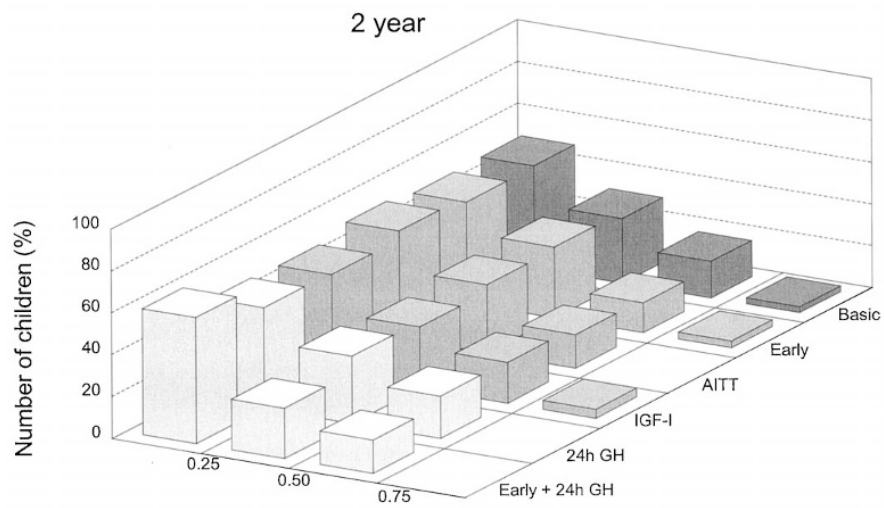

| Observed $\triangle$ SDS - Predicted $\triangle$ SDS |

Figure 3. Absolute difference (irrespective of sign) between observed and predicted change in height SDscore after $1 \mathrm{y}(t o p)$ and 2 y (bottom) of GH treatment calculated with the different models for the children in the validation group. With the $\mathrm{GH}_{24}$ Early model $84 \%$ of the 1 st y growth response was predicted within 0 to 0.25 SDscore, and between 0.25 to 0.50 SDscore for the remaining $16 \%$. With the Basic model the 1 st y growth response could be predicted within 0 to 0.25 SDscore for $73 \%$ of the children, within 0.25 to 0.50 SDscore for $23 \%$, and within 0.5 to 0.75 score for $5 \%$.

range, the overall prediction results outside the modeling range were excellent, adding credibility to the prediction models. The prediction intervals, expressed as $\pm 1.96 \times \mathrm{SD}_{\text {res }}$ were for the 
1 st $y \pm 0.37$ to \pm 0.54 SDscores with the different models. Corresponding values for the 2 nd y prediction were \pm 0.55 to \pm 0.76 SDscores. Figure 4 shows the prediction intervals from different models for a boy from the validation group.

\section{Comparison with Linear Multivariate Statistical Method}

A multiple stepwise linear regression analysis was applied to the same variables as in the models described above. An algorithm was constructed for each model, using the variables and regression coefficients found. These algorithms were used to predict the growth responses of children in the validation group and compared with the observed growth response. When comparing the $\mathrm{SD}_{\text {res }}$ values from the nonlinear validation with the linear method, the $\mathrm{SD}_{\text {res }}$ values from the former validation results were substantially lower, giving a more accurate prediction. For the Basic model, the validation $\mathrm{SD}_{\text {res }}$ for the 1st $\mathrm{y}$ was 0.327 using the linear approach and 0.241 using the nonlinear approach; corresponding results for the $2-\mathrm{y} \mathrm{SD}_{\text {res }}$ were 0.535 and 0.363 , respectively.

\section{DISCUSSION}

This study derives and presents validated models that can be used in individual children to predict the initial 1- and 2-y growth response to a given GH treatment regimen in short children with a broad range in GH secretory capacity. The precision of these models is the best to date, as estimated by the narrow individual prediction interval. Thus, the models will serve as a valuable tool for selecting children for successful GH treatment, and allow better evidence-based decision making with regard to growth promoting treatment. The value of our prediction study is enhanced by the use of one group of children to develop, and a strictly separate group of children fulfilling the inclusion criteria coming from different endocrine centers in Sweden to validate the models, i.e. "temporal validation," the second step out of three according to Altman and Royston (14). The third step, external validation of the models using data from children from other countries, is in progress.

Five sets of clinical information were used. A Basic model was based solely on auxological data from the year before treatment was started, and parental heights. The other models, which included the Basic model plus data on growth in early life (before 2 y of age) and/or biochemical measures, result in three levels of prediction accuracy. While the auxological data provide a means for predicting growth responses, additional pretreatment investigations can be selected to improve the accuracy of prediction. In our hands, the accuracy with which the growth response to GH could be predicted was the same using the models that included the AITT, IGF-I, or the early infancy growth data, with only a minor improvement compared with Basic model. This may indicate that these variables already were substantially reflected by the auxology variables included in the Basic model. The predictive value was improved, however, when the $\mathrm{GH}_{\max } 24 \mathrm{~h}$ data were added to the Basic model.

The model having the narrowest prediction interval, was the one using the 24-h GH profile data added to Basic + early growth model. Using this model, gain in height after $1 \mathrm{y}$ of GH treatment could be predicted with an accuracy of \pm 0.37 SDscores $\left( \pm 1.96 \mathrm{SD}_{\text {res }}\right)$. For a 3-y-old boy, 1 SDscore is 3.2 $\mathrm{cm}$, which corresponds to a prediction interval of $\pm 1.2 \mathrm{~cm}$. For a boy aged $9 \mathrm{y}$, the mean age at start of GH treatment in the present study, 1 SDscore is $5.3 \mathrm{~cm}$. Therefore a prediction
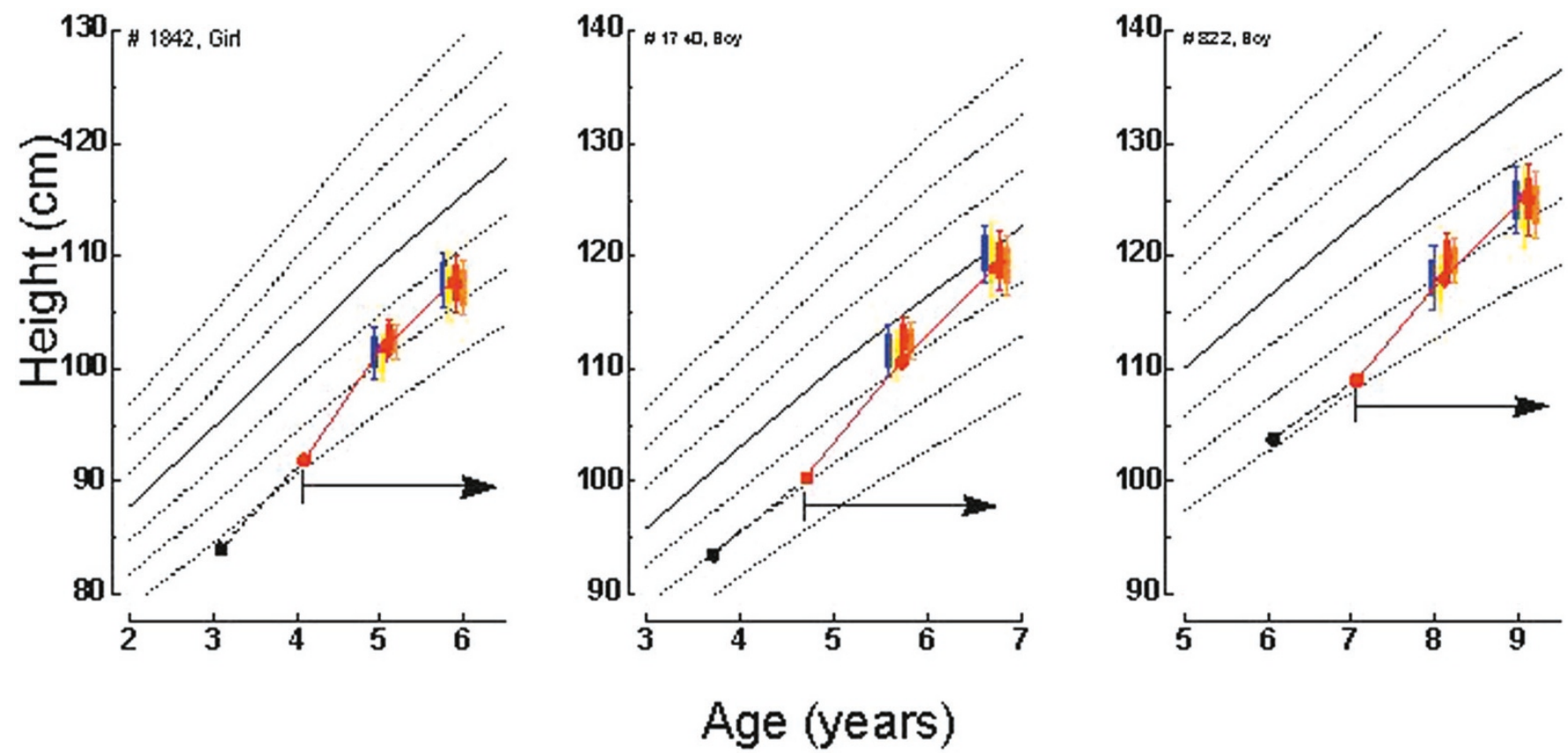

Figure 4. The $95 \%$ prediction intervals for three children from the validation group, calculated at the start of treatment with the Basic model (left symbol of each set), the early growth model (middle left), the $\mathrm{GH}_{24 \mathrm{~h}}$-model (middle right), and the $\mathrm{GH}_{24 \mathrm{~h}}$ early growth model (right symbol of each set). The bar represents $\pm 1 \mathrm{SD}$ and the whiskers $\pm 1.96 \mathrm{SD}$. The actual growth before treatment (dotted line) and during treatment (solid line) is presented in a growth chart, with growth curve lines indicating mean (solid line) and $\pm 3 \mathrm{SD}$ (dotted lines). 
interval of $\pm 2.0 \mathrm{~cm}$ would be anticipated (32). Using the Basic model, which relies solely on auxology, the 1 st y prediction interval was \pm 0.54 SDscore, corresponding to $\pm 1.7 \mathrm{~cm}$ for a 3 -y-old child and $\pm 2.9 \mathrm{~cm}$ for a child aged $9 \mathrm{y}$. Thus there is a choice between different work up procedures depending on accuracy demanded. The improvement of the prediction interval measured in $\mathrm{cm}$ may not be impressing, but measured in percentage it is substantial. Even more important is that the $\mathrm{SD}_{\text {res }}$ for the group is presented. The low value is a sign of the low ratio of extreme residuals, i.e. high accuracy for individual children. The less accuracy in the model used, the less reliable is the prediction and the higher the risk to make a wrong clinical decision for the individual child about a treatment with considerable cost for the community and effort for the child. Extra time and expense for work up is low compared with the cost and effort for $1 \mathrm{y}$ of treatment.

The finding that the GH peak from the 24-h profile was more informative than the peak from the provocation test may reflect the higher reproducibility of the former (33-35). Results from provocation tests show low reproducibility and wide intraindividual variability, partly due to total or partial refractoriness of the somatotrophs at the time the test is performed (36). Moreover, the GH value obtained during the spontaneous profile better reflects physiologic secretion and the overall secretory pattern. Growth in children has been shown to be modulated by the GH pulse amplitude $(23,37,38)$. This is supported by our results, in which the GH peak is more informative than other estimates from the GH profile. In a recent study in which leptin was measured as a metabolic marker for the lipolytic effect of $\mathrm{GH}$, the change in serum leptin level was shown to correlate with the growth responses indicating that metabolic effects may parallel effects on bone growth (13). Unfortunately, we had insufficient numbers of children with serum leptin measurements to include leptin as a variable in the present models.

The multivariate approach reflects the clinical considerations and has been used in earlier studies with prediction models (39-41). The approaches used in the present study are similar to those used for children in the world database KIGS by Ranke et al. $(39,42,43)$, although some differences exist. In previous studies, the children were separated according to the maximum GH level during a provocation test into those with GHD and those with ISS; the statistical method used was linear multivariate analysis; and the GH dose was not uniform because of the different treatment modalities used world-wide. The latter, of course, has the benefit of providing insight into the effects of individual GH treatment modalities. The forthcoming question will be: what minimal growth response justifies treatment with use of what maximal GH dose, in relation to benefit, safety, and cost.

While the models in this study only predict the 1- and 2-y growth responses of individual children to $\mathrm{GH}$ treatment, they also provide insight into the final outcome: adult height. The short time period was selected because it is the period for catch-up growth, as reported in children with celiac disease or late-onset primary hypothyroidism $(44,45)$, and we believe it is a suitable model for catch-up growth in GHD children being treated with GH. The 1st y growth response is an indicator of growth to come (46). This 1 st y growth influences markedly the height achieved by the onset of puberty, an important determinant of adult height $(47,48)$. During analysis of our data, we developed a model for prediction of the 2 nd y growth response by including the 1st y growth response variable. Including the 1st y data made all other variables unnecessary, as the prediction was quite reliable (data not shown). Thus, the bulk of information about the GH responsiveness is obtained from the growth response during the first $y$.

In keeping with criteria established for other therapies in medicine, the short or slowly growing child should not be denied GH therapy solely based on results of tests of GH secretion. Rather, decisions about treatment with GH should be made on the basis of the likelihood of benefit, depending not only on the sufficiency of GH secreted, but also on the responsiveness to GH. In a declining economy, there is temptation to return to older diagnostic criteria that use lower cut-off $\mathrm{GH}$ values in provocation tests, despite their well known shortcomings. The models presented here permit estimation of $\mathrm{GH}$ responsiveness with an accuracy that substantially improves on the clinical diagnostic procedures used hitherto, and facilitates selection of children who will respond to GH treatment. The models presented here are validated for children judged as having ISS or GHD by classical criteria. Therefore, neither wide variability in responses to a $\mathrm{GH}$ provocation tests nor arbitrarily chosen cut-off limits, preclude their use.

Acknowledgments. The authors thank their colleagues in the Swedish Study Group for GH Treatment for fruitful discussions, for caring for the patients, and for providing the reports from clinical trials on GH treatment in short children in Sweden. The Swedish Study Group for GH Treatment consists of: K. Albertsson Wikland, J. Alm, S. Aronsson, J. Gustafsson, L. Hagenäs, A. Häger, S. Ivarsson, B. Kriström, C. Marcus, C. Moëll, K.O. Nilsson, M. Ritzén, T. Tuvemo, U. Westgren, O. Westphal, and J. Åman. We also thank our colleagues participating in the National Registry for GH treatment. Special thanks are due to our pediatric colleagues in the region of Western Sweden: Drs S. Adolfsson, M. Bergström, H. Fors, U. Jansson, P.O. Lübeck, and H. Tollig for collaboration and referring most of the patients who underwent complete investigations, and to our colleagues at the GP-GRC, collaborating in the clinical work: O. Westphal, R. Bjarnason, J. Dahlgren, L. Gelander, and E. Norjavaara; in the laboratory, C. Löfqvist and L. Larsson; and in the ward, C Axelson. We also thank Dr. W. Blum for the IGF-I and IGFBP-3 assays.

\section{REFERENCES}

1. Saggese G, Ranke MB, Saenger P, Rosenfeld RG, Tanaka T, Chaussain JL, Savage MO 1998 Diagnosis and treatment of growth hormone deficiency in children and adolescents: Towards a consensus. Horm Res 50:320-340

2. Ranke MB 1996 Towards a consensus on the definition of idiopathic short stature. Horm Res 45(suppl 2):64-66

3. Wit JM, Boersma B, de Muinck Keizer-Schrama SMPF, Nienhuis HE, Oostdijk W, Otten BJ, Delemarre-van de Waal HA 1995 Long-term results of growth hormone therapy in children with short stature, subnormal growth rate and normal growth hormone response to secretagogues. Clin Endocrinol (Oxf) 42:365-372

4. Goddard AD, Covello R, Luoh S-M, Clackson T, Attie KM, Gesundheit N, Rundle AC, Wells JA, Carlsson LMS 1995 Mutations of the growth hormone receptor in children with idiopatic short stature. N Engl J Med 333:1093-1098 
5. Attie MK, Carlsson LMS, Rundle AC, Sherman BM 1995 Evidence for partial growth hormone insensitivity among patients with idiopatic short stature. J Pediatr 127:244250

6. Laron Z 1995 Prismatic cases: Laron Syndrome (Primary Growth Hormone Resistance) from patient to laboratory to patient. J Clin Endocrinol Metab 80:1526-1531

7. Savage MO, Woods KA 1996 The investigation of growth hormone insensitivity. Clin Endocrinol (Oxf) 45:257-260

8. Wyatt DT, Mark D, Slyper A 1995 Survey of growth hormone treatment practices by 251 pediatric endocrinologists. J Clin Endocrinol Metab 80:3292-3297

9. Ranke MB, Haber P 1996 Growth hormone stimulation tests. In: Ranke MB (ed) Diagnostics of endocrine function in children and adolescents. Johann Ambrosius Barth Verlag, Heidelberg Leipzig, pp 134-148

10. Kriström B, Karlberg J, Albertsson Wikland K 1995 Prediction of the growth response of short prepubertal children treated with growth hormone. Acta Paediatr Scand 84:51-57

11. Rosenfeld RG, Albertsson Wikland K, Cassorla F, Frasier DS, Hasegawa Y, Hintz RL, Lafranchi S, Lippe B, Loriaux L, Melmed S, Preece MA, Ranke MB, Reiter EO, Rogol AD, Underwood LE, Werther GA 1995 Diagnostic controversy: the diagnosis of childhood growth hormone deficiency revisited. J Clin Endocrino Metab 80:1532-1540

12. Kriström B, Jansson C, Rosberg S, Albertsson Wikland K 1997 Growth response to growth hormone $(\mathrm{GH})$ treatment relates to serum insulin-like growth factor I (IGF-I) and IGF-binding protein-3 in short children with various GH secretion capacities. J Clin Endocrinol Metab 82:2889-2898

13. Kriström B, Carlsson B, Carlsson LMS, Albertsson Wikland K 1998 Short term changes in serum leptin levels provide a strong metabolic marker for the growth response to growth hormone treatment in children. J Clin Endocrinol Metab 83:2735-2741

14. Altman DG, Royston P 2000 What do we mean by validating a prognostic model? Stat Med 19(4):453-473

15. Kriström B, Jansson C, Svensson B, Rosberg S, Nierop AFM, Albertsson Wikland K 1997 Growth response to growth hormone treatment is possible to predict. Horm Res 48:74

16. Tanner JM, Whitehouse RM 1976 Clinical longitudinal standards for height, weight, height velocity, weight velocity and stages of puberty. Arch Dis Child 51:170-202

17. Zachmann M, Prader A, Kind HP, Häflinger H, Budlinger H 1974 Testicular volume during adolescence. Cross-sectional and longitudinal studies. Helv Paediatr Acta 29:61-72

18. Karlberg J, Engström I, Karlberg P, Fryer JG 1987 Analysis of linear growth using a mathematical model. I. From birth to three years. Acta Paediatr Scand $76: 478-488$

19. Albertsson Wikland K, Rosberg S 1988 Analyses of 24-hour growth hormone profiles in children: relation to growth. J Clin Endocrinol Metab 67:493-500

20. Karlberg P, Taranger J, Engström I, Karlberg J, Landström T, Lichtenstein H, Lindström B, Svennberg-Redegren I 1976 Physical growth from birth to 16 years and longitudinal outcome of the study during the same age period. Acta Paediatr Scand 258:7-76

21. Karlberg J, Albertsson Wikland K 1996 Nutrition and linear growth in childhood. In: Bindels JG, Goedhardt AC, Visser HKA (eds) Recent Developments in Infant Nutrition. Kluwer Academic Publishers, London, pp 112-127

22. Albertsson Wikland K, Jansson C, Rosberg S, Novamo A 1993 Time-resolved immunometric assay of human growth hormone. Clin Chem 39:1620-1625

23. Albertsson Wikland K, Rosberg S, Karlberg J, Groth T 2011994 Analysis of 24-hour growth hormone profiles in healthy boys and girls of normal stature: relation to puberty. J Clin Endocrinol Metab 78:1195-1201

24. Jansson C, Boguszewski C, Rosberg S, Carlsson LMS, Albertsson Wikland K 1997 Growth hormone (GH) assays: influence of standard preparations, GH isoforms, assay characteristics, and GH-binding protein. Clin Chem 43:950-956

25. Merriam GR, Wachter KW 1982 Algorithms for the study of episodic hormone secretion. Am J Physiol 243:E310-E318

26. Albertsson Wikland K, Rosberg S, Libre E, Lundberg LO, Groth T 1989 Growth hormone secretory rates in children as estimated by deconvolution analysis of 24-h plasma concentration profiles. Am J Physiol 257:E809-E814

27. Albertsson Wikland K, Rosberg S 1996 Methods of evaluating spontaneous growth hormone secretion. In: Ranke MB (ed) Diagnostics of Endocrine Function in Children and Adolescents. Johann Ambrosius Barth Verlag, Heidelberg Leipzig, pp 149-175
28. Blum WF, Breier BH 1994 Radioimmunoassays for IGFs and IGFBPs. Growth Regul 4:11-19

29. Boguszewski M, Jansson C, Rosberg S, Albertsson Wikland K 1996 Changes in serum insulin-like growth factor I and IGF-binding protein-3 levels during growth hormone treatment in prepubertal short children born small for gestational age. J Clin Endocrinol Metab 81:3902-3908

30. Gifi A 1990 Nonlinear Multivariate Analysis. Wiley, Chichester, p 58

31. Bradley J 1968 Distribution Free Statistical Test. Prentice-Hall, Inc, London, pp $76-78$

32. Karlberg J 1989 A biologically-oriented mathematical model (ICP) for human growth. Acta Paediatr Scand Suppl 350:70-94

33. Tassoni P, Cacciari E, Cau M, Colli C, Tosi M, Zucchini S, Cicognani A, Pirazzoli P, Salaradi S, Balsamo A, Frejaville E, Cassio A, Zappulla F 1990 Variability of growth hormone response to pharmacological and sleep tests performed twice in short children. J Clin Endocrinol Metab 71:230-234

34. Albertsson Wikland K, Rosberg S 1992 Reproducibility of 24-h growth hormone profiles in children. Acta Endocrinol 126:109-112

35. Martha PM, Rogol AD, Veldhuis JD, Blizzard RM 1996 A longitudinal assessment of hormonal and physical alterations during normal puberty in boys. III. The neuroendocrine growth hormone axis during late prepuberty. J Clin Endocrinol Metab $81: 4068-4074$

36. Gelander L, Albertsson Wikland K 1989 Growth hormone (GH) release after administration of GH-releasing hormone in relation to endogenous 24-h GH secretion in short children. J Endocrinol 122:61-68

37. Hindmarsh P, Smith PJ, Brook CGD, Matthews DR 1987 The relationship between height velocity and growth hormone secretion in short prepubertal children. Clin Endocrinol (Oxf) 27:581-591

38. Mauras N, Blizzard RM, Link K, Johnson ML, Rogol AD, Veldhuis JD 1987 Augmentation of growth hormone secretion during puberty. Evidence for a pulse amplitude-modulated phenomenon. J Clin Endocrinol Metab 64:596-601

39. Ranke MB, Guilbaud O, Lindberg A, Cole T 1993 Prediction of the growth response in children with various growth disorders treated with growth hormone: analysis of data from the Kabi Pharmacia International Growth Study. Acta Paediatr 82:S391:82-88

40. Blethen SL, Compton P, Lippe BM, Rosenfeld RG, August GP, Johanson A 1993 Factors predicting the response to growth hormone (GH) therapy in children with $\mathrm{GH}$ deficiency. J Clin Endocrinol Metab 76:574-579

41. Spagnoli A, Spadoni GL, Cianfarani S, Pasquino AM, Troiani S, Boscherini B 1995 Prediction of the outcome of growth hormone therapy in children with idiopatic short stature. J Pediatr 126:905-909

42. Ranke MB, Guilbaud O 1991 Growth response in prepubertal children with idiopathic growth hormone deficiency during the first two years of treatment with human growth hormone. Analysis of the Kabi Pharmacia International Growth Study. Acta Paediatr Scand 379:109-115

43. Ranke MB, Lindberg A, Chatelain P, Wilton P, Cutfield W, Albertsson Wikland K, Price DA 1999 Derivation and validation of a mathematical model for predicting the response to exogenous recombinant human growth hormone $(\mathrm{GH})$ in prepubertal children with idiopathic GH deficiency. J Clin Endocrinol Metab $84: 1174-1183$

44. Damen GM, Boersma B, Wit JM, Heymans HSA 1994 Catch-up growth in 60 children with coeliac disease. J Pediatr Gastroenterol Nutr 19:394-400

45. Ranke MB, Schwarze CP, Mohnike K, von Mühlendahl KE, Keller E, Willgerodt H, Kiess W 1998 Catch-up growth after childhood-onset substitution in primary hypothyroidism: is it a guide towards optimal growth hormone treatment in idiopathic growth hormone deficiency? Horm Res 50:264-270

46. Ranke MB, Lindberg A, Guilbaud O 1994 Prediction of growth in response to treatment with growth hormone. In: Ranke MB, Gunnarsson R (eds) Progress in Growth Hormone Therapy - 5 Years of KIGS. J \& J Verlag, Mannheim, pp 97-111

47. Rikken B, Massa GG, Wit JM 1995 Final height in a large cohort of Dutch patients with growth hormone deficiency treated with growth hormone. Dutch Growth Hormone Working Group. Horm Res 43:135-137

48. Blethen SL, Baptista J, Kuntze J, Foley T, LaFranchi S, Johanson A 1997 Adult height in growth hormone $(\mathrm{GH})$ deficient children treated with biosynthetic $\mathrm{GH}$ $\mathrm{J}$ Clin Endocrinol Metab 82:418-420 


\section{APPENDIX}

Algorithms for the models

\section{Predicted Change in Height SDscore ( $\triangle$ HSDS) during GH Treatment}

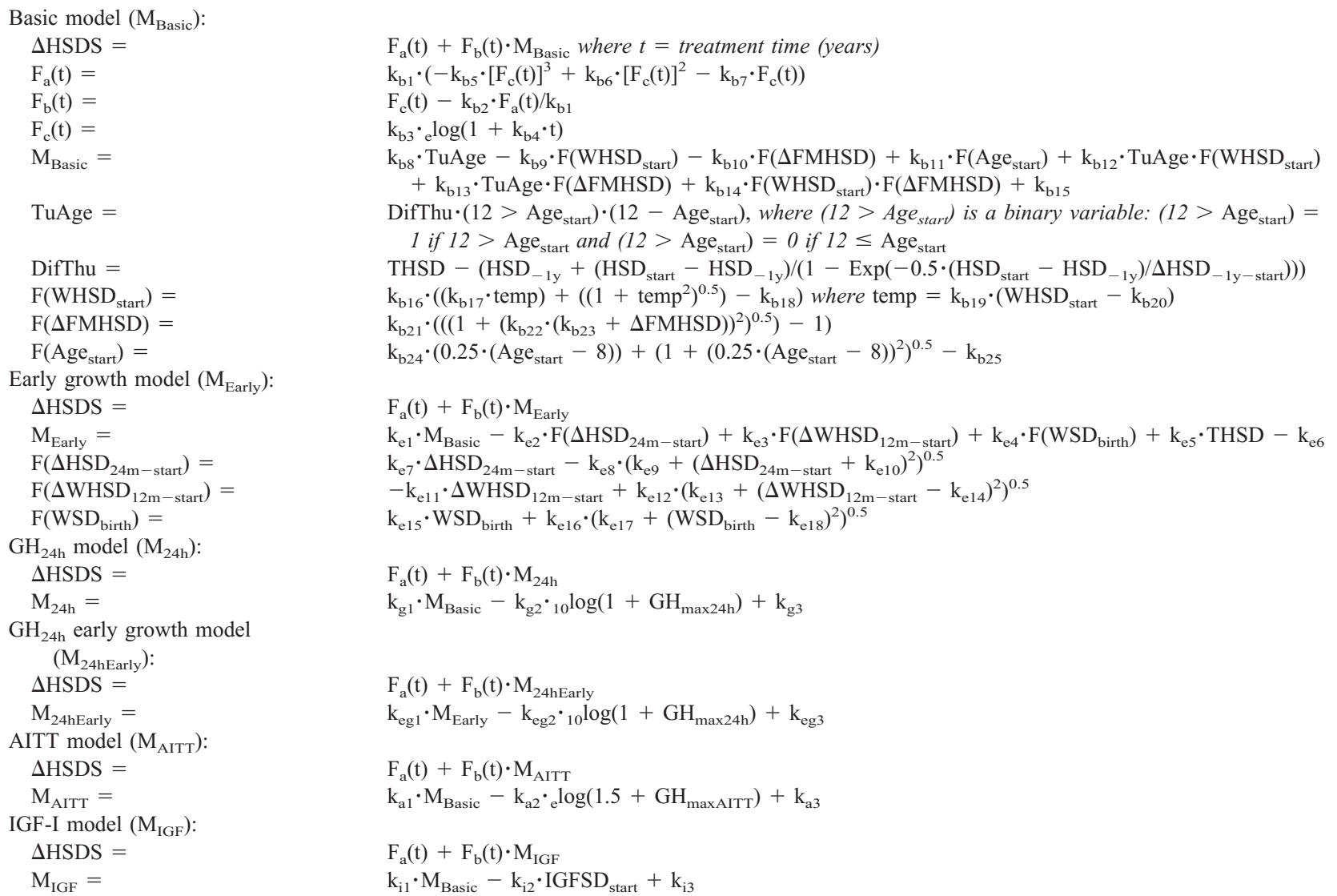

Variable

WHSD $_{\text {start }}$

$\triangle$ FMHSD

Age $_{\text {start }}$

THSD

$\mathrm{HSD}_{-1 \mathrm{y}}$

$\mathrm{HSD}_{\text {start }}$

$\Delta \mathrm{HSD}_{-1 \mathrm{y}-\text { start }}$

$\Delta \mathrm{HSD}_{24 \mathrm{~m}-\text { start }}$

$\Delta \mathrm{WHSD}_{12 \mathrm{~m}-\text { start }}$

WSD $_{\text {birth }}$

$\mathrm{GH}_{\max 24 \mathrm{~h}}$

$\mathrm{GH}_{\max \text { AITT }}$

IGFSD $_{\text {start }}$
Explanation

Weight for height SDscore at GH start

Difference between fathers and mothers heights in SDscore

Age at GH start in years

Target height SDscore corrected for sex of the child

Height SDscore one year before GH start

Height SDscore at GH start

Change in height SDscore during pretreatment year

Change in height SDscore from $24 \mathrm{~m}$ of age to $\mathrm{GH}$ start

Change in weight for height SDscore from $12 \mathrm{~m}$ of age to $\mathrm{GH}$ start

Weight in SDscore at birth

Maximal GH value during the $24 \mathrm{~h}$ profile

Maximal GH value during the AITT test

IGF-I value in SDscore at GH start

\section{Coefficients}

\begin{tabular}{|c|c|c|c|c|c|}
\hline $\mathrm{k}_{\mathrm{b} 1}=0.31685$ & $\mathrm{k}_{\mathrm{b} 2}=0.1799$ & $\mathrm{k}_{\mathrm{b} 3}=0.55$ & $\mathrm{k}_{\mathrm{b} 4}=1.3$ & $\mathrm{k}_{\mathrm{b} 5}=1.762$ & $\mathrm{k}_{\mathrm{b} 6}=6$ \\
\hline $\mathrm{k}_{\mathrm{b} 7}=3.239$ & $\mathrm{k}_{\mathrm{b} 8}=0.02916$ & $\mathrm{k}_{\mathrm{b} 9}=0.25932$ & $\mathrm{k}_{\mathrm{b} 10}=0.36816$ & $\mathrm{k}_{\mathrm{b} 11}=0.77074$ & $\mathrm{k}_{\mathrm{b} 12}=0.27671$ \\
\hline $\mathrm{k}_{\mathrm{b} 13}=0.07831$ & $\mathrm{k}_{\mathrm{b} 14}=3.60133$ & $\mathrm{k}_{\mathrm{b} 15}=1.26972$ & $\mathrm{k}_{\mathrm{b} 16}=0.77$ & $\mathrm{k}_{\mathrm{b} 17}=0.11$ & $\mathrm{k}_{\mathrm{b} 18}=0.99$ \\
\hline $\begin{array}{l}\mathrm{k}_{\mathrm{b} 19}=0.32 \\
\mathrm{k}_{\mathrm{b} 25}=0.993\end{array}$ & $\mathrm{k}_{\mathrm{b} 20}=0.23$ & $\mathrm{k}_{\mathrm{b} 21}=1.4$ & $\mathrm{k}_{\mathrm{b} 22}=0.4$ & $\mathrm{k}_{\mathrm{b} 23}=0.23$ & $\mathrm{k}_{\mathrm{b} 24}=0.12$ \\
\hline $\mathrm{k}_{\mathrm{e} 1}=0.73526$ & $\mathrm{k}_{\mathrm{e} 2}=2.00211$ & $\mathrm{k}_{\mathrm{e} 3}=1.92051$ & $\mathrm{k}_{\mathrm{e} 4}=0.21613$ & $\mathrm{k}_{\mathrm{e} 5}=0.0781$ & $\mathrm{k}_{\mathrm{e} 6}=0.26128$ \\
\hline $\mathrm{k}_{\mathrm{e} 7}=0.68832$ & $\mathrm{k}_{\mathrm{e} 8}=0.72541$ & $\mathrm{k}_{\mathrm{e} 9}=0.02191$ & $\mathrm{k}_{\mathrm{e} 10}=0.05894$ & $\mathrm{k}_{\mathrm{e} 11}=0.24767$ & $\mathrm{k}_{\mathrm{e} 12}=0.96885$ \\
\hline $\mathrm{k}_{\mathrm{e} 13}=0.02751$ & $\mathrm{k}_{\mathrm{e} 14}=0.05334$ & $\mathrm{k}_{\mathrm{e} 15}=0.65889$ & $\mathrm{k}_{\mathrm{e} 16}=0.75224$ & $\mathrm{k}_{\mathrm{e} 17}=1.12504$ & $\mathrm{k}_{\mathrm{e} 18}=0.51335$ \\
\hline $\mathrm{k}_{\mathrm{g} 1}=0.75649$ & $\mathrm{k}_{\mathrm{g} 2}=0.63914$ & $\mathrm{k}_{\mathrm{g} 3}=1.28683$ & & & \\
\hline $\mathrm{k}_{\mathrm{eg} 1}=0.74412$ & $\mathrm{k}_{\mathrm{eg} 2}=0.72007$ & $\mathrm{k}_{\mathrm{eg} 3}=1.41778$ & & & \\
\hline $\mathrm{k}_{\mathrm{a} 1}=0.86222$ & $\mathrm{k}_{\mathrm{a} 2}=0.25917$ & $\mathrm{k}_{\mathrm{a} 3}=1.07792$ & & & \\
\hline $\mathrm{k}_{\mathrm{i} 1}=0.79248$ & $\mathrm{k}_{\mathrm{i} 2}=0.08808$ & $\mathrm{k}_{\mathrm{i} 3}=0.17274$ & & & \\
\hline
\end{tabular}

